\title{
Is Commercial Culture Popular Culture?: A Question for Popular Communication Scholars
}

\author{
Matthew P. McAllister \\ Virginia Tech
}

\begin{abstract}
This essay compares commercial culture with popular culture, reviewing different conceptualizations of the terms. It posits that there are significant differences, but that commercial culture increasingly intrudes on other forms of culture. The essay argues that popular communication scholars are well positioned to develop new perspectives and techniques to understand hybrid versions of popular-commercial culture. Watts and Orbe's (2002) concept of "spectacular consumption" is discussed as 1 such example of a new perspective that sheds light on recent forms. The essay concludes with a brief description of 2 examples of spectacular consumption, Super Bowl advertising and Cheerios Play Books.
\end{abstract}

Commercial culture may be a lot of things. It may be a subset of consumer culture. It may be a defining element of mass culture. It may even at times be high culture or "art," as Berger (2000) and advertising creatives (Soar, 2000) have contended. But, at least conceptually, the answer to the title of this essay is no: Commercial culture is not the same thing as popular culture. This stance can be qualified and is not universally shared. But several scholars of popular communication emphasize the importance for the popular of such concepts as participatory texts, authenticity, and genuine pleasure, elements that may be less central to the commercial.

So if they are not the same thing, why should advertising — as an intense form of commercial culture- be a topic of future exploration in the journal Popular Communication? The commercial form should be studied under this rubric because of the impact commercial culture has on specific forms of popular culture. Communication scholarship, with its emphasis on the power of the message, its mix of re-

Requests for reprints should be sent to Matthew P. McAllister, Associate Professor, Department of Communication Studies, Virginia Tech, Blacksburg, VA 24061-0311. E-mail: mattm@vt.edu 
ceiver- and sender-based modes of understanding, and its interdisciplinary roots and nature, may offer unique insight into this commercial impact. In addition, industrial practices and trade discourse often assume the two forms of culture are the same thing, and there are many social and economic forces that are pushing commercial and popular culture together. Whatever form of culture or communication that is coming out of this centripetal process should be studied with many of the same theoretical, critical, and methodological tools that define the best scholarship in popular communication and popular culture. This scholarship also shows great potential to develop new techniques and theories to grasp the ever-changing nature and growing influence of commercial culture.

Many of the assumptions about the differences between the two forms of culture come down to definition, of course. Commercial culture, for example, can be defined as both commercial culture or commercial culture. Commercial culture is the more far-reaching one, but also the one that does not necessarily involve as a central tenet the integration of advertising forms with entertainment. This version, closely related to the idea of "mass culture," refers to culture that results from a commercial system, a system where the profit motive overwhelmingly dominates. Heavy-duty marketing, corporate ownership, and predictable production processes of cultural products are involved. By this definition, commercial culture is huge. It would include the big blockbuster film, the highly promoted network television show, and the mass-market paperback romance novel.

To eliminate this category of culture from notions of "the popular" excludes a lot of cultural forms and is therefore a potentially contentious definition. Nevertheless, such claims are found. Arguing for the importance of a distinction between mass commercial culture and popular culture is Stephen Duncombe (1997) in his thoughtful discussion of "zines" as underground culture. For Duncombe, popular culture is strongly associated with another kind of culture, "participatory culture," and for him the idea of authenticity is central. From his perspective, mass commercial culture is neither participatory nor authentic. He contended that

Commercial culture is not popular culture. It may be popular, but its popularity is a means to an end: that of being a profitable commodity. As a result, fans are continually betrayed in their quest to make the culture theirs, and the process of connection must be continually reinvented, ad infinitum. (p. 113)

Duncombe's discussion of commercial culture assumes commercial culture is mass culture. For him, a key issue is that popular culture is authentically popular - created by those who find pleasure in the culture and use it to understand and change their lives. Duncombe distinguished between popular culture that arises in such an authentic way and commercial culture that is manufactured to be popular. Duncombe's book, then, links underground culture with the notion of the popular; 
zines are a form of grassroots popular culture that often exists as a reaction to artificial and unauthentic commercial cultural forms.

A bit narrower definition of commercial culture, one that is the focus of the remainder of this essay, may find agreement with a larger number of scholars when arguing for its exclusion from notions of the popular. Commercial culture is not as broad but more deeply commercialistic. The definition here is similar to the definition of "commercialization" offered by Mosco (1996): a "process that specifically refers to the creation of a relationship between an audience and an advertiser" (p. 144). This definition of commercial culture overlaps with consumer culture, with the latter also including shopping activities and the geography of retail space. Commercial culture, then, refers specifically to advertising forms of mediated culture: culture designed to sell a product. By this definition, advertisements are commercial culture. Commercial culture also results when obvious advertising and promotional influences intrude on nonadvertising forms. Big blockbuster films like Spider-Man (2002) become commercialized through such techniques as product placement (one Spider-Man scene features the utility of Dr. Pepper cans for web shooter target practice) and merchandising tie-ins (such as Spider-Man Toasted Oat cereal and Spider-Man Pop-Tarts). The television show becomes commercial culture when it is used to promote advertisers or other entertainment holdings, such as a 2002 Ford-sponsored reality-based program on the WB network using a Ford ad slogan, "No Boundaries," as the name of the program. The book becomes commercial culture when an advertiser pays to have its product featured prominently in a book, such as jewelry maker Bulgari's commissioning of Fay Weldon to write The Bulgari Connection, featuring at least 34 mentions of Bulgari (Arnold, 2001).

Scholars have argued that commercial culture and popular culture offer significant differences and may be in fact mutually exclusive. Assumptions about what popular culture is often arise out of such comparisons. For example, although Jib Fowles (1996) in his book, appropriately titled (for this essay) Advertising and Popular Culture, saw the two as "allied symbol systems" (p. xiv), much of the book is spent comparing and contrasting the two forms of communication, arguing that "advertising, while sharing many attributes with popular culture, is a categorically different sort of symbolic content" (p. 11). By highlighting advertising's self-serving nature, the spectator's skeptical gaze, and more contained content forms (the 30-sec commercial, for instance), Fowles contrasted popular culture as more pleasure oriented and appropriated more eagerly by audiences.

When other scholars compare commercial culture and popular culture, they imply these distinctions but concentrate on how commercial culture has affected and will continue to affect the forms and functions of popular culture. Even when discussions of popular culture include advertising, they often do so hesitantly and with the key notion of advertising intruding on popular culture. The Popular Culture Association, known for its exploration (and celebration, at times) of popular 
culture, has a long-standing Advertising Division. Some presentations in that division may have indeed argued that advertising is legitimate popular culture. However, in Advertising and Popular Culture (same title, different book from the previously discussed Fowles, 1996), which published samples from the Advertising Division, the editor argued that advertising scholars at the Popular Culture Association "highlight advertising's impact on culture and society," implying a distinction from advertising as popular culture (Danna, 1992, n.p.). Similarly, in her discussion of "popular advertising" as a topic under the umbrella of the Popular Communication Division of the International Communication Association, Zelizer (2000) argued that scholars in this tradition "complicate [italics added] the meaning of advertising in its popular dimensions" (p. 308), rather than explore or discuss advertising's placement in the popular domain.

In this light, critics often highlight the dominance of the commercial in the popular, raising issues of commercial intrusion, ubiquitous stereotyping, commodity fetishism and consumer hegemony, and the reduction of nonconsumeristic perspectives in other forms of culture. It should be pointed out that not all scholars of advertising find such trends to be troublesome or believe that consumerist forms necessarily lead to a devalued culture. Obviously, in business-oriented outlets, many advertising scholars take an administrative point of view by doing research designed to enhance the promotional effectiveness of techniques such as sponsorship and product placement (see, for example, Brennan, Dubas, \& Babin, 1999; Miyazaki \& Morgan, 2001). Other scholars who come from a liberal arts point of view do not believe that the expanding commercialism in society is necessarily a destructive trend, but rather argue that such influence is a necessary evil for media financing (Richards \& Murphy, 1996), that critical scholars exaggerate the destructive influence of advertising (Fowles, 1996; Twitchell, 1996), or that active interpretative and performative strategies by consumers can actually enhance citizenship (Meijer, 1998). There is, nevertheless, an established tradition of scholarship that explores the destructive nature of commercial culture (a very noninclusive list of recent work includes Andersen \& Strate, 2000; Croteau \& Hoynes, 2001; Ewen, 2000; Klein, 1999; Shields with Heinecken, 2002).

In fact, criticism of commercial culture has developed rapidly since the early 1980s. Although some of this is due to the growth of critical perspectives in media studies during this time, another reason involves the obvious pervasiveness of commercial culture and advertising in modern society. Several factors have encouraged the cultivation of consumerist forms and aggressive advertising and promotion since the early 1980s, and critics have noticed these trends. One example is technology such as the remote control (Bellamy \& Walker, 1996) and recording devices like VCRs and TiVO (Bernstein, 2001), which have decreased the primacy of the 30-sec spot advertisement and encouraged marketers to develop other more invasive techniques. Other technologies, like cable, satellite television, and the Internet have created more ways to advertise, more competition for advertising 
revenue, and more opportunities for integrated marketing campaigns among new and established promotional vehicles. The opening of global markets via the spread of capitalism after the end of the Cold War and privatization of national media systems has also opened new promotional venues (McAllister, 1997).

Besides these elements facing advertisers, corporate media are increasingly promoting themselves more aggressively than in the past (McAllister, 2000). The competition for audiences introduced by additional entertainment technologies increases the salience of promoting media products. In addition, with the growth of large media corporations (encouraged by such factors as globalization, regulatory permissiveness, and the need for technological "convergence"), corporations such as AOL-Time Warner and Disney look for ways to promote through "synergies": cross-promotional opportunities using several of their owned media outlets. Critics have expressed concern about the political clout of such mega-media corporations, the decrease of diversity, and, most relevant to this essay, the subordination of content to the promotional function that such synergy encourages (Alger, 1998; Bagdikian, 2000; Barnouw et al., 1997; Croteau \& Hoynes, 2001; McChesney, 1999).

Thus we have a double whammy of selling incentives in modern commercial culture at the turn of the millennium: advertisers encouraged to be aggressive because of such factors as technology on the one hand, and media encouraged to be more promotionally oriented due to increased competition and corporate cross-promotional opportunities on the other. The ubiquity of commercial culture means that scholars interested in the intersection of commercial and the popular need to develop new critical concepts and techniques to study the ever-changing hybrid forms of advertising and promotion that have developed and will continue to develop in this hyper-commercialized environment. These new forms may involve traditional notions of the popular (as audience members embrace such forms), as well as traditional notions of commercial culture (a heavy consumerist orientation and a confusing mixture of popular cultural forms with advertising and promotional goals).

One such promising new critical concept advanced by Watts and Orbe (2002) is "spectacular consumption." In an article that deconstructs the very popular Budweiser "Whassup?!" campaign, they argued that, given their popularity, the beer commercials (and the discourse that surrounded the commercials, such as personal appearances by the commercial's actors) required a new way to understand commercial discourse. The authors developed the idea of spectacular consumption using as a touchstone the work of the French Situationalist Guy Debord, who argued that the idea of consumerist "spectacle" was a dominant form of capitalist representation. Often applied to massive sports events (Gruneau, 1989; McAllister, 1998), the idea of the spectacle, as Watts and Orbe pointed out, includes an integration of the "authentic"-which as noted is an important concept in many scholarly definitions of popular culture-with massive displays of promo- 
tion and consumption styles. As they argued, "The consuming rhetoric of the spectacle thus promotes a contradiction as it seeks strategically to reproduce on a massive scale the singularity associated with the "authentic" (Watts \& Orbe, 2002, p. 4). The approach they use also is suited for complex forms of commercial culture in that it involves more than one method. Their analysis of the "Whassup?!" spectacle utilizes political economy, textual criticism, and focus group interviews to understand the campaign's appeal for both industrial forces and multiple audiences. The multiperspectival and multimethodological concept of spectacular consumption, then, is a helpful model in analyzing commercial phenomena that is popular and widely loved, that is high commodified, and that appears in many different forms other than the 30 -sec commercial.

In 1996, when writing about another example of spectacular consumption, the Energizer Bunny campaign, Fowles (1996) observed that "Widespread acceptance of the bunny led to an infrequent occurrence in advertising, a breakthrough of the advertising symbol back into popular culture" (p. 7). Fowles's claim about the rarity of such phenomena seems a bit quaint for the 2000s. Examples of advertisements that spread out to other cultural forms occur fairly regularly now. This essay concludes with a brief discussion of two such examples of commercial breakout and spectacular consumption: Super Bowl advertising and children's books based on brand-name cereals and snack foods. The key here is not just the crassly commercial nature of these examples, but also their intrusion into other forms of culture besides the circumscribed television commercial or print ad and their seemingly enthusiastic embrace by media audiences.

\section{SUPER BOWL COMMERCIALS}

It is now a cliché to say that one watches the Super Bowl for the commercials more than for the game. The cliché has an increasingly fertile grain of truth behind it. According to surveys of Super Bowl viewers, in 1996 only $2 \%$ watched the game exclusively for the commercials; in 1998 the figure was $7 \%$; in 2002 it was more than $10 \%$ (McAllister, 1999; Taylor, 2002). Much of the reason for this increased popularity may be the publicity that Super Bowl commercials receive. The news media play up the hype of Super Bowl advertising with pregame anticipatory stories and postgame analyses focusing on the commercials. Typically, for example, each of the three United State's broadcast network news morning programs air segments discussing and rerunning the promotional "Tops and Flops" from the night before.

Super Bowl ads are also packaged as a free-standing form of entertainment away from the game. On February 1, 2002, the Friday evening before the FOX Super Bowl, another network, CBS, aired Super Bowl's Greatest Commercials $I I$, a sequel to the special that aired the year earlier. Apparently, CBS believed that the risk of promoting a competitor's programming was worth the potential 
gain in ratings, advertiser goodwill, and internal promotion. Besides being an hour-long bonus for Super Bowl advertisers (and therefore potential CBS advertisers) and promotional partner USA Today, the program also was heavily promotional for CBS in that the two hosts were actors on the network's prime-time program Yes, Dear. The Super Bowl ad program was also promoted on both the CBS Web site and the USA Today Web site.

In essence, the program was nothing but an hour of commercials: 45 old Super Bowl commercials shown and celebrated in the show, and 28 new commercials shown during the "commercial breaks" (an ironic term in this context). But was this just ham-handed commercialism designed to stroke advertisers, or was it spectacular consumption as Watts and Orbe (2002) defined the term? In fact, the show was quite popular for that time slot, ranking as the 47 th most-watched program that week, attracting 9 million viewers. This was 3 million more than the previous year's "original" Super Bowl's Greatest Commercials; with these numbers, the 2002 sequel was labeled a ratings "winner" by The Washington Post the next week (de Moraes, 2002). Tellingly, the 46th most-watched program that week immediately followed the CBS program that Friday night. It was an ABC special entitled The Best Commercials You've Never Seen (and Some You Have) 7 (!), hosted by the Budweiser "Whassup?!" actors, the commercial stars of the 2000 Super Bowl. The textual characteristics of such commercial texts, the ways programs like this may influence what it means to be "popular," the networks' view of the future of such programs, and audience readings of these shows are issues highlighted by the spectacular consumption perspective.

\section{CHEERIOS PLAY BOOKS}

Cheerios was not the first company to release a children's book based on a food brand: 1994's The M\&M Brand Counting Book may hold that distinction ("Snacks as Bestsellers," 2000). However, books in the Cheerios line (like the Cheerios Play Book) have sold millions of copies (Fulmer, 2000). Appealing to a fairly universal children's desire to "play with your food," the Cheerios books encourage children to place Cheerios in certain places on a page to help complete a picture. From an economic perspective, the books help spark sales and establish brand loyalty by linking the cereal with fun activity and cute drawings. They also, of course, tout in a general way the idea of consumption. The $\$ 6$ books, available in most sizable book stores, are essentially retail-based advertisements for the cereal themselves. In The Cheerios Animal Play Book, a spin-off from the original (joining The Cheerios Counting Book and The Cheerios Halloween Play Book), the word Cheerios actually only appears once in the book, but 14 times on the book's outside cover. Inside the book is a 50-cent coupon for Cheerios with an invitation to visit www.cheerios.com, "A Great On-Line Parenting Source.” At this Web site, 
one finds "Honey Nut Cheerios Cholesterol News," a link about the Cheerios-sponsored NASCAR (also available as a toy car), and opportunities to buy other Cheerios books and merchandise. Again, perspectives like spectacular consumption may help us to understand the cross-media appeal and impact of this hybrid version of commercial and popular culture.

This essay began by arguing that popular culture and commercial culture are theoretically distinct. The former emphasizes the authenticity of popular pleasure whereas the latter emphasizes the subservience of the sales pitch to cultural forms. What the previous examples of spectacular consumption imply is that this theoretical distinction may be increasingly difficult to maintain when examples of the popular without the commercial are growing more rare and the commercial routinely achieves the popularity of the popular. Highly rated television specials about commercials and best-selling books about breakfast cereal may seem especially blunt, but their popularity highlight how the blurring of various cultural categories-popular, mass, commercial, and consumer-is enacted in everyday life.

Such examples and the issues they raise are all the more reason why popular communication scholars must continue to study the commercial. Multiple theoretical, methodological, and perspectival approaches, which the communication discipline often cultivates, are needed to explore the implications of the morphing forms of commercial culture and to develop critical tools and concepts to understand the implications of such forms for the ideological and democratic dimensions of people's lives. Scholars interested in popular communication are well positioned to contribute mightily to our understanding of commercial culture.

\section{REFERENCES}

Alger, D. (1998). Megamedia: How giant corporations dominate mass media, distort competition, and endanger democracy. Lanham, MD: Rowman \& Littlefield.

Andersen, R., \& Strate, L. (Eds.). (2000). Critical studies in media commercialism. New York: Oxford University Press.

Arnold, M. (2001, September 13). Making books: Placed products, and their cost. The New York Times, p. E3.

Bagdikian, B. (2000). The media monopoly (6th ed.). Boston: Beacon.

Barnouw, E., Aufderheide, P., Cohen, R. M., Frank, T., Gitlin, T., Lieberman, D., Miller, M. C., Roberts, G., \& Schatz, T. (1997). Conglomerates and the media. New York: The New Press.

Bellamy, R. V., \& Walker, J. R. (1996). Television and the remote control: Grazing on a vast wasteland. New York: Guilford.

Berger, A. A. (2000). Ads, fads, and consumer culture: Advertising's impact on American character and society. Lanham, MD: Rowman \& Littlefield.

Bernstein, P. (2001, April 2). Sponsor's message is medium. Variety, p. 13.

Brennan, I., Dubas, K. M., \& Babin, L. A. (1999). The influence of product-placement type and exposure time on product-placement recognition. International Journal of Advertising, 18, 323-337.

Croteau, D., \& Hoynes, W. (2001). The business of media: Corporate media and the public interest. Thousand Oaks, CA: Pine Forge. 
Danna, S. R. (1992). Advertising and popular culture: Studies in variety and versatility. Bowling Green, OH: Bowling Green State University Popular Press.

de Moraes, L. (2002, February 6). Fox airs the Super Bowl. Fox wins the week. The Washington Post, p. C7.

Duncombe, S. (1997). Notes from underground: Zines and the politics of alternative culture. London: Verso. Ewen, S. (2000). Memoirs of a commodity fetishist. Mass Communication \& Society, 4, 439-452.

Fowles, J. (1996). Advertising and popular culture. Thousand Oaks, CA: Sage.

Fulmer, M. (2000, March 26). Food marketers cashing in by turning brands into books, toys. The Los Angeles Times, p. C4.

Gruneau, R. (1989). Making spectacle: A case study in television sports production. In L. A. Wenner (Ed.), Media, sports and society (pp. 134-154). Newbury Park, CA: Sage.

Klein, N. (1999). No logo: Taking aim at the brand bullies. New York: Picador.

McAllister, M. P. (1997). Sponsorship, globalization, and the Summer Olympics. In K. T. Frith (Ed.), Undressing the ad: Reading culture in advertising (pp. 35-63). New York: Peter Lang.

McAllister, M. P. (1998). College bowl sponsorship and the increased commercialization of amateur sports. Critical Studies in Mass Communication, 15, 357-381.

McAllister, M. P. (1999). Super Bowl advertising as commercial celebration. The Communication Review, 3, 403-428.

McAllister, M. P. (2000). From flick to flack: The increased emphasis on marketing by media entertainment corporations. In R. Andersen \& L. A. Strate (Eds.), Critical studies in media commercialism (pp. 101-122). New York: Oxford University Press.

McChesney, R. W. (1999). Rich media, poor democracy: Communication politics in dubious times. Urbana: University of Illinois Press.

Meijer, I. C. (1998). Advertising citizenship: An essay on the performance power of consumer culture. Media, Culture, \& Society, 20, 235-249.

Miyazaki, A. D., \& Morgan, A. G. (2001). Assessing market value of event sponsoring: Corporate Olympic sponsorships. Journal of Advertising Research, 41(1), 9-15.

Mosco, V. (1996). The political economy of communication. Thousand Oaks, CA: Sage.

Richards, J. I., \& Murphy, J. H. (1996). Economic censorship and free speech: The circle of communication between advertisers, media, and consumers. Journal of Current Issues and Research in Advertising, 18, 121-134.

Shields, V. R., with Heinecken, D. (2002). Measuring up: How advertising affects self image. Philadelphia: University of Pennsylvania Press.

Snacks as bestsellers. (2000, November). Prepared Foods, p. 27.

Soar, M. (2000). Encoding advertisements: Ideology and meaning in advertising production. Mass Communication \& Society, 3, 415-437.

Taylor, J. (2002, February 2). Commercials take on life of their own Super Bowl. The Omaha World-Herald, p. D1.

Twitchell, J. B. (1996). Adcult USA: The triumph of advertising in American culture. New York: Columbia University Press.

Watts, E. K., \& Orbe, M. P. (2002). The spectacular consumption of "true" African American culture: "Whassup" with the Budweiser guys? Critical Studies in Media Communication, 19(1), 1-20.

Zelizer, B. (2000). Popular communication in the contemporary age. In W. B. Gundykunst (Ed.), Communication yearbook 24 (pp. 297-316). Thousand Oaks, CA: Sage. 